\title{
The Countervailing Effect of Language Proficiency and Cultural Adaptation on the Frequency of Cognitive-Metacognitive Strategies among EFL Readers
}

\author{
Ebrahim Daryaee Motlagh \\ MA in TEFL, Shahid Beheshti University
}

\begin{abstract}
This article is an attempt to investigate how advanced and high-intermediate learners of English receiving culturally familiar or nativized contents may differ in terms of both their performance in reading comprehension and the use of cognitive and metacognitive strategies. To this end, a total of 73 advanced and high-intermediate students of English were selected and assigned to two groups in order to acquire relevant data across different levels of language proficiency. Subsequently, the participants received culturally adapted texts with sociologically, semantically and pragmatically nativized contents in the form of narrative and expository texts. Following this step, the participants were given reading comprehension tests and cognitive-metacognitive questionnaires. While culturally familiar texts are generally believed to have facilitating impacts on the overall reading comprehension for all language groups, the findings of the present study suggest that the advanced learners of English may use these strategies more frequently compared to high-intermediate learners of English. These results may raise strong implications concerning the suitability and effectiveness of nativized or culturally adapted materials for learners at varying levels of language proficiency.
\end{abstract}

KEYWORDS: Language proficiency, nativization, cultural familiarity, reading comprehension, reading strategies

\section{INTRODUCTION}

A great deal of research has been dedicated to reading comprehension due to its importance not only in academic settings but also in daily life. This particular skill is also one of the major areas of research and analysis in ELT pedagogy. In general terms, reading comprehension involves the ability to infer meaning from texts and linguistic symbols and the appropriate interpretation of such information (see, for instance, Aebersold \& Field, 1997; Goodman, 1988; Gough, 1999; Grabe \& Stoller, 2002; Harrison, 2004; Jackson, 2005; Samuels \& Kamil, 1988; Stanovich, 2000). Based on this general definition, this skill has been analyzed and studied from contrasting angles including the behaviorist perspectives which view the reader as a passive decoder (Chastain, 1988; Nuttall, 1996) and the cognitivist perspectives which consider the reader to be actively involved in the construction of meaning (Aebersold \& Field, 1997; Grabe \& Stoller, 2002). Moreover, in scholarly attempts and research conducted to offer a definition for reading skills, the status of readers' background knowledge and their reading comprehension strategies have always been stressed by scholars throughout different decades (Abu-Rabia, 1998; Carrell, 1983; Keshavarz \& Atai, 2007; Landry, 2002; Levine \& Haus, 1985; Moy Yin, 1985).

As regards reading comprehension, background knowledge is usually construed as cultural schema. Arguably, the schema is comprised mainly of abstract and relevant mental structures which are generally organized based on one's prior experiences (Carrell 1987; Chastain 1988; Nuttall 1996). The results of some research studies have demonstrated that this organized and abstract knowledge plays a key role in the comprehension of texts and linguistic symbols as readers usually tend to retrieve relevant background information to extrapolate the intended meaning in a passage (Grabe, 1991; Nuttall, 1996). Yet another subject that comes to light in the study of reading comprehension and cultural schema is 'reading strategies'. There seems to be a general consensus that these strategies are "specific actions, behaviors, steps or techniques" (Scarcella \& Oxford, 1992, p. 63) and must be harnessed systematically by fluent readers in order to comprehend English texts efficiently and effectively (Coiro \& Dobler, 2007). Accordingly, these endeavors generally fall into two categories, namely cognitive and metacognitive strategies. According to O'Malley and Chamot, cognitive strategies are "operations and steps in learning or problem solving that require direct analysis, transformation or synthesis of learning materials" (O’Malley \& Chamot, 1990, p. 99). On the other hand, metacognitive strategies have been described 


\section{International Journal of Current Science Research and Review}

ISSN: 2581-8341

Volume 04 Issue 01 January 2021

DOI: 10.47191/ijcsrr/V4-i1-08, Impact Factor: 6.825

IJCSRR@ 2021

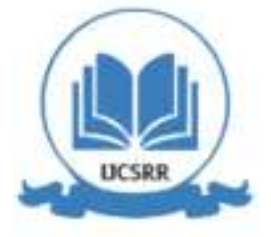

www.ijcsrr.org

as "actions which go beyond purely cognitive devices and which provide a way for learners to coordinate their own learning process" (Oxford, 1990, p. 136).

As indicated earlier, studying the relationship between background knowledge and reading comprehension among English learners has received a great deal of attention over the last three decades (see, for more details, Johnson, 1982; Oller, Chihara \& Sakurai, 1989; Lee, 1986; Langer, 1984; Droop \& Verhoeven, 1998; Abu-Rabia, 1998; Alptekin, 2006; Sasaki, 2000; Erten \& Razi, 2009; Huang 2009; Parry, 1996). This being said, there seems to be some questions about the actual effect of culture on the use of cognitive and metacognitive strategies by proficient or high-intermediate learners of English who are mainly given the so-called authentic and original texts with an expository or narrative style. In other words, the role of language proficiency in EFL/ESL learners should be considered along with the possibility of facilitated reading comprehension through nativized or culturally familiar contents. Furthermore, there are only a few studies addressing the facilitating or otherwise neutral effects of culture on the use of comprehension strategies particularly for advanced or high-intermediate learners of English (see, for more discussion, O’Malley \& Chamot, 1990). Perhaps understandably, native or authentic materials are usually welcomed by educationalists in language pedagogy while nonnative or adapted texts are frowned upon. On the other hand, nativized and culturally familiar materials seem to be gaining popularity in some societies (Erten \& Razi, 2009; Keshavarz \& Atai, 2007) while it is not clear how the advanced or high-intermediate leaners may benefit from such materials and how their language proficiency can play a mediating or countervailing role in the use of cognitive or metacognitive strategies. With this in mind, the present article is an attempt to investigate the facilitative or debilitative effects of language proficiency and cultural familiarity on the use of cognitive and metacognitive strategies among advanced and highintermediate readers.

\section{REVIEW OF LITERATURE}

It has been asserted throughout the literature and there is evidence to suggest that the process of reading comprehension can be facilitated by developing texts, passages and materials that are adapted to the learners' native culture (Alptekin, 2006). Moreover, there is no shortage of research on language and culture and a great deal of research has been dedicated to the investigation of the intertwined relationship between these two factors (see, for instance, Abu-Rabia, 1998; Atkinson, 1999; Brown, 1994; Carrell, 1991; Carson et al., 1990; Chamot, 2004; Davis \& Bistodeau, 1993; El-Dib, 2004; Erten \& Razi, 2009; Fiorito, 2000; Fuhong, 2004; Genc \& Bada, 2005; Hansen-Strain, 1989; Jiang, 2000; Kachru \& Smith, 2008; Kaikkonen, 1997; Menard-Warwick, 2009; Oller et al., 1988; Parry, 1996; Pritchard, 1990; Sasaki, 2000; Sowden, 2007; Tsou, 2005; Van Oord, 2005). Nevertheless, the facilitative role of culture in this context has been approached differently by language scholars resulting in a panoply of context-bound answers. Among other studies, some particular studies have focused on the kind of reading strategies employed by readers in an EFL or ESL context (Phakiti, 2003a; 2003b; 2008) whereas other studies have mainly focused on discrepancies in reading strategies such as cognitive and metacognitive strategies across different cultural groups (Van Oord, 2005; Sowden, 2007).

However, the earliest marks of this approach to language learning and material development can be traced back to the 1980s and the experimental research on the impact of culture on reading comprehension. For example, Oller et al. (1988) prepared and used two original texts one of which had been modified based on the original context in order to compare the performance of Japanese students in reading comprehension exams. The results suggested that modified or adapted texts in which certain textual elements were modified could enhance the participants' performance significantly. Similarly, Sasaki (2000) conducted an epoch-making study on the effects of schemata and culturally familiar words on the students' performance in cloze test results. The results of Sasaki's study showed that those participants receiving culturally familiar cloze texts outperformed their peers who were given unmodified texts with culturally unfamiliar words. Similar findings were also confirmed in the research performed by Abu-Rabia (1998) and Fuhong (2004). In one interesting case, Abu-Rabia (1998) investigated the relationship between the cultural background of Arab students residing in Israel and their performance on reading comprehension tests. In this study, a number of short stories were prepared based on Jewish and Arab cultures and the results indicated the better performance of those students receiving texts from their own cultural setting compared with their peers who received culturally unfamiliar texts. Following the same line of research, Fuhong (2004) conducted another study with the participation of Catholic-Hispanic and Muslim-Arab language learners who received two different sets of texts based on their Muslim and Catholic-oriented heritage and the findings of this study also showed that the test-takers were more competent in the comprehension of culturally familiar contents. As mentioned earlier, there 


\section{International Journal of Current Science Research and Review}

ISSN: 2581-8341

Volume 04 Issue 01 January 2021

DOI: 10.47191/ijcsrr/V4-i1-08, Impact Factor: 6.825

IJCSRR@ 2021

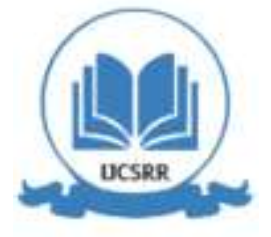

www.ijcsrr.org

is no shortage of research on the relationship between reading comprehension and cultural familiarity and the results often suggest that the latter has an evidently facilitative role.

Regardless, most studies that have focused on the use of reading strategies by different cultural groups are limited in the sense that they disregard the role of language proficiency at different levels. On the other hand, there are still questions about the efficacy of culturally modified texts prepared for this purpose. For instance, these questions gained popularity in the 1990s in the United States and some scholars began to focus on cross-linguistic differences among speakers of different languages with different nationalities. In one of these studies, Pritchard (1990) used think-aloud protocols in examining such differences and it was found that contrasting strategies were employed by American and Palauan readers when they studied texts in their own native language. Likewise, Davis and Bistodeau (1993) conducted a study to highlight possible differences between American and French students who read texts in English or French. They concluded that these subjects used reading strategies differently in these contexts. Another study conducted by Parry (1996) with two groups of Nigerian and Chinese participants yielded similar results that lent support to the fact that cultural background was a determining factor in reading strategies. In this case, it was later observed that the Nigerian participants get involved in top-down methods to decode the texts while their Chinese counterparts preferred bottom-up methods. Later, following the same line of inquiry, Erten and Razi (2009) focused on the relationship between cultural familiarity and the comprehension of short stories. Once again, their conclusions corroborated the findings in previous research.

Generally, the review of relevant literature seemingly suggests that most of the research in this area has focused almost extensively on reading strategies and more recently on cognitive and metacognitive strategies. Nonetheless, the effects of cultural schema have received less attention with regard to the advanced and high-intermediate learners of English who read narrative and expository texts. To contribute to this line of research, the present article investigates how these learners of English who receive culturally familiar and nativized contents may differ in terms of their performance in reading comprehension while using cognitive and metacognitive strategies.

\section{RESEARCH METHOD}

\section{3-1. Participants}

Primarily, the participants of this research consisted of 80 BA students of English Language Translation at Islamic Azad University in the city of Bushehr in Iran. As these participants were familiar with the English language, they were in a position to work more comfortably with the data elicitation instruments designed to provide the necessary data. Of these subjects, 73 students (44 males and 29 females) aged 19 to 24 were able to give the necessary data. Due to attrition, some of the participants chose not to participate in the research and, therefore, a mismatch occurred between the original and final number of participants. The researcher used an ex-post facto design to divide these subjects into two groups based on their language proficiency (i.e. advanced and highintermediate levels) which had been determined by the reading sections in a TOEFL test. Based on performance descriptors for the TOEFL test, the advanced reading scores fall between 24 and 30 whereas high-intermediate reading scores fall between 18 and 23. In this process, 35 students were assigned to the upper-intermediate group and 38 students were assigned to the advanced group based on their scores on this language proficiency test. Both groups received nativized expository and narrative texts throughout the course of research. In this case, expository texts are usually information-based samples while narrative texts often relate a series of events such as news stories.

\section{3-2. Instruments}

In this research, the elicitation of data was performed using the following instruments. On the one hand, a number of reading comprehension tests were used with original and authentic passages which later underwent a nativization process based on the Iranian culture. Alptekin defines this process as "the sociological, semantic and pragmatic adaptation of the textual and contextual clues of the original text into the language learner's own culture, while keeping its linguistic and rhetorical content essentially intact" (Alptekin, 2006, p. 499). Following this definition, the selected passages were textually and contextually included in the process. For instance, general words and items which dealt with locations, places, characters, and jobs were nativized at the textual adaptation stage. On the other hand, culture-specific items and cues were targeted at the level of contextual clues. In this regard, the author followed the nativization process introduced by Alptekin (2006) at three levels of culture (i.e. sociological, semantic and pragmatic levels). In this case, nativized religious words can be regarded as contextual clues and cultural values can be viewed as pragmatic cues while culture-specific structures or notions fall into the realm of semantic cues. 


\section{International Journal of Current Science Research and Review}

ISSN: 2581-8341

Volume 04 Issue 01 January 2021

DOI: 10.47191/ijcsrr/V4-i1-08, Impact Factor: 6.825

IJCSRR@ 2021

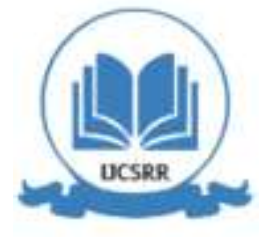

www.ijcsrr.org

On the other hand, a Likert scale questionnaire of cognitive and metacognitive strategies was employed in this study. This 35-point Likert scale was originally designed by Phakiti (2003b; 2008). The use of this questionnaire was deemed appropriate as it mainly focuses on reading skills following the "theory of human information processing" (Phakiti, 2008, p. 248). Furthermore, after covering the texts, the researcher also used 40 multiple-choice reading comprehension items to assess the participants' comprehension of nativized texts.

\section{3-3. Procedure}

In the preliminary course of research, a pilot test was carried out with a relatively small number of participants $(\mathrm{N}=33)$. The aim of this test was to use the data to identify and discard those test items that were either too difficult or too easy. It must be noted that the language proficiency of those taking this pilot test matched the proficiency of research participants based on the results of a TOEFL test. Finally, the results of the pilot test conducted with this small sample demonstrated that the difficulty of items was appropriate. Moreover, the reliability of these tests was confirmed using cronbach's alpha which indicated an acceptable alpha value for nativized and culturally adapted texts $(\alpha=.85)$. Finally, the research was implemented and each participant was given a package consisting of nativized texts (i.e. expository and narrative texts), reading comprehension tests based on the passages and the cognitivemetacognitive questionnaire. In order to demonstrate their reading abilities more accurately, the participants were not allowed to use a dictionary and were asked to hand in their smart phones before the test. They were asked to answer the reading tests first and complete the questionnaires later based on their reading performance. Finally, the researcher scored the tests of reading comprehension and the questionnaire after receiving the package.

\section{3-4. Data analysis}

In this study, the researcher conducted an independent sample t-test to analyze the data and check if there are any significant differences between the two groups in terms of the participants' performance on reading comprehension tests. Furthermore, the procedure known as repeated-measure ANOVA was conducted to evaluate the use of cognitive-metacognitive strategies among advanced and high-intermediate participants. In the final analysis, the effect size measure ( $\eta 2)$ was also considered in the analysis of the association between variables and the effects of the independent variable.

\section{RESULTS AND DISCUSSION}

\section{4-1. Results}

As regards the participants' performance in the comprehension tests with nativized and culturally adapted texts, the results of an independent sample t-test showed that the advanced readers outperformed high-intermediate readers; however, their better performance is marked by a narrow margin showing a fragile superiority in test results $\left(\mathrm{t} \_((71))=2.46\right.$, $\left.\mathrm{p}<.05\right)$. As observed in Table 1, the mean score of the advanced group of participants $(\overline{\mathrm{x}}=16.80, \mathrm{SD}=1.69)$ is a little higher than the mean score of the high-intermediate group of participants $(\overline{\mathrm{x}}=15.82, \mathrm{SD}=2.21)$.

Table 1: The t-test results showing the performance gap between advanced and high-intermediate participants

\begin{tabular}{|l|c|c|c|c|c|c|}
\hline Language proficiency grou & $\mathrm{N}$ & Mean & $\mathrm{SD}$ & $\mathrm{t}$ & $\mathrm{df}$ & Sig (2 tailed) \\
\cline { 1 - 5 } Advanced & 38 & 16.80 & 1.69 & -2.46 & 71 & .01 \\
\cline { 1 - 5 } High-Intermediate & 35 & 15.82 & 2.21 & & & \\
\hline
\end{tabular}

The main objective of the present study was to investigate the possible differences among advanced and high-intermediate EFL readers as far as the use of cognitive or metacognitive strategies is concerned in comprehending nativized or culturally familiar texts. As mentioned earlier, the general assumption in the relevant literature is that readers with a better command of English (i.e. advanced readers) would use these strategies to a lesser extent as they would encounter fewer challenges in reading comprehension. The results of the Analysis of Variance (ANOVA) showed that cognitive-metacognitive strategies both indicated a significant main effect $\left(F_{-}((1,71))=126.82, p<.05\right)$. However, it was found that the interaction between the advanced and high-intermediate group and the strategies employed by the readers is not significant $\left(F_{-}((1,71))=.32, p>.05\right)$. Following this finding, it was also found that $60 \%$ of the variability in test performance in advanced and high-intermediate groups was attributable to cognitive and metacognitive strategies as indicated by the eta squared ( 12$)$ measure. 


\section{International Journal of Current Science Research and Review}

ISSN: 2581-8341

Volume 04 Issue 01 January 2021

DOI: 10.47191/ijcsrr/V4-i1-08, Impact Factor: 6.825

IJCSRR@ 2021

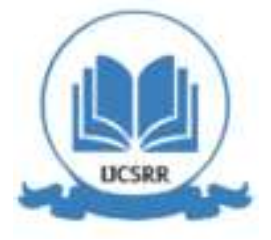

www.ijcsrr.org

Descriptive data analysis has shown the obverse of the general assumption in the literature. In this sense, unlike the popular belief that more advanced EFL readers engage in reading strategies to a lesser extent due to their higher proficiency, the high-intermediate readers receiving the nativized and culturally adapted texts resorted to both cognitive and metacognitive strategies less than their advanced counterparts (Table 2). Based on the data, advanced readers seem to have utilized a repertoire of cognitive and metacognitive strategies to deal with nativized texts.

Table 2: Descriptive statistics showing the use of cognitive and metacognitive strategies by participants

\begin{tabular}{|l|l|l|l|c|}
\hline Strategies & Groups & N & Mean & SD \\
\hline Metacognitive & Advanced & 38 & 61.75 & 10.11 \\
& High-intermediate & 35 & 51.03 & 10.22 \\
\hline Cognitive & Advanced & 38 & 53.55 & 8.55 \\
& High-intermediate & 35 & 41.98 & 9.78 \\
\hline
\end{tabular}

\section{4-2. Discussion}

Broadly speaking, the results presented above lend support to the widely admitted fact that familiarity with the cultural load of a text causes a facilitating effect in the process known as reading comprehension. However, readers at different levels of language proficiency may have perceived this effect differently and thus the present research aimed at the use of both cognitive and metacognitive strategies by advanced and high-intermediate students encountering pragmatically, sociologically or semantically manipulated or "nativized" texts. By definition, cognitive strategies are put forward in the process of reading comprehension when readers who make sense of culturally unfamiliar contents with new information must use cognitive strategies extensively to bridge the gap between the source and target cultures (Phakiti, 2003a). In other words, expository or narrative texts with their culturally unfamiliar contents may cause EFL readers to use cognitive strategies more frequently; therefore, the absence or lower levels of such strategies in comprehending nativized texts have been considered as a sign of general preference for culturally familiar content. A review of literature suggests that these strategies have a compensatory role in dealing with problematic elements from the target language that are perhaps slightly above their current level of comprehension (see, for instance, O’Malley \& Chamot, 1990; Oxford, 1990). Therefore, with respect to what was discussed earlier, the data elicited from the comprehension tests and questionnaires should have logically corroborated this theory. More specifically, following this logic, advanced readers should resort to compensatory cognitive-metacognitive strategies to a lesser extent compared with readers having lower levels of proficiency. Nonetheless, in this study, the group consisting of advanced readers employed these strategies more frequently than their counterparts in the high-intermediate group when they received culturally adapted texts. Their overall performance on reading comprehension tests did not show a striking superiority; rather, the results indicate that they only outperformed the high-intermediate group by a small margin. This particular finding is not quite in line with the general assumption that culturally adapted or nativized texts are always better than the so-called authentic texts (see, Phakiti, 2003a; ) at least for more advanced readers who may have developed related cultural schemata in dealing with the target language input.

These results give prominence to another aspect of the literature on reading comprehension and textual nativization which suggests that EFL readers eventually acquire and develop relevant schemata whether through cultural assimilation or abundant exposure to the target culture. Arguably, this cultural awareness occurs naturally somewhere along the path towards language mastery (see, for instance, Hansen-strain, 1989). Therefore, based on the results of this study, it can be argued that advanced readers outweighed the high-intermediate readers in terms of using cognitive and metacognitive strategies as they experienced the interference of elements from their native culture in target language inputs. This can be explained by the fact that both groups received the same culturally adapted reading texts but advanced readers resorted to metacognitive strategies to recheck the constructed meaning. For these participants, the prominent role of metacognition or simply "cognition of cognition" was evident in decoding the texts (see, for more discussion on this term, Carrel, Pharis \& Liberto, 1989). Technically, it is believed that the use of cognitive strategies by language learners also involve the use of metacognitive ones to check the recreated meaning (Oxford, 1990; Coiro \& Dobler, 2007). In this sense, these categories are often used together to help the readers in decoding textual cues. While all language groups may benefit from the so-called authentic and original texts, advanced students seem to be among those who enjoy these benefits more generally. Of course, the results of this study may not be readily generalizable and there is need for more research on the role of language 


\section{International Journal of Current Science Research and Review}

ISSN: 2581-8341

Volume 04 Issue 01 January 2021

DOI: 10.47191/ijcsrr/V4-i1-08, Impact Factor: 6.825

IJCSRR@ 2021

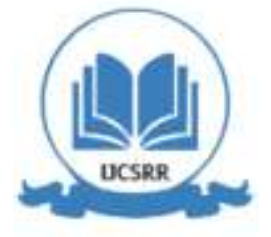

www.ijcsrr.org

proficiency, cultural familiarity and text nativization with a larger sample population and preferably different language levels. This being said, the mean score differences between the groups might show some strong implications about the overuse of nativized or culturally adapted materials. This seems to have been the dominant pattern in the last decades since the popularity of text nativization in the 1990s (Oller et al., 1989; Parry, 1996; Carrell, 1991; Davis \& Bistodeau, 1993; Abu-Rabia, 1998; Chamot, 2004; Carson et al., 1990; Erten \& Razi, 2009; El-Dib, 2004; Fuhong, 2004; Hansen-Strain, 1989; Pritchard, 1990; Sasaki, 2000). Based on the findings of the current study, it can be discussed that the removal or substitution of what is perceived to be the cultural elements of the target language might not offer the proper or ultimate solution in the development of reading abilities even though this upward trend is encouraged by some language policies. Following this discussion, the role of ideological or state policies in controlling or diminishing the purported effects of foreign cultures has been the subject of robust research in English as a foreign language. This trend has been observed in some societies more than others due to the intertwined role of language learning and culture.

\section{CONCLUSION}

As mentioned earlier, this research was an attempt to investigate how language proficiency among English students (e.g. advanced and high-intermediate EFL readers) may affect their performance in reading comprehension and the use of cognitive and metacognitive strategies in response to culturally familiar or nativized contents. Having received culturally adapted and sociologically, semantically, and pragmatically nativized texts in the form of narrative and expository texts, the results of reading comprehension tests and cognitive-metacognitive questionnaires were discussed. Following these discussions and findings, it can be concluded that the advanced learners of English may even use these strategies more frequently compared to high-intermediate learners. Moreover, the performance of advanced English learners in the comprehension of expository and narrative texts might not change drastically after receiving nativized materials. While culturally familiar or nativized texts have been given a lot of credit in some aspects of the literature in facilitating the overall reading comprehension for all language groups, this study concludes that such effects may not emerge consistently at varying levels of language proficiency. These findings cannot be generalized to all contexts in which the question of cultural familiarity and nantivization is discussed. However, the findings may offer some insight for all teachers, language practitioners and particularly curriculum developers to reevaluate the time, cost and energy invested in similar projects. These conclusions may also have general implications in the field of applied linguistics. It appears that learners' dependence on textual cues representing cultural items from the source language will eventually prove to be minimal because these learners become proficient in reading English texts containing target language cues. Following this constructivist paradigm, familiarity with different cultures is part of the growth for a language learner and advanced learners of English show some aspects of this growth. On the other hand, it can also be concluded that the effects of native or nativized materials on EFL learners' reading comprehension can be still quite relevant for high-intermediate readers, as these participants used cognitive or metacognitive strategies to a lesser extent in this study. Therefore, for some language teachers, native textbooks (e.g., sources with original or authentic texts) should be exploited with caution as their impacts on language learners' reading comprehension are context-bound. Obviously, this study can be replicated with participants from other majors or levels of language proficiency to achieve generalizable results. Furthermore, as some differences have been reported between male and female EFL readers from the perspective of reading strategies discussed in this article (Phakiti, 2003a, 2003b), the effects of gender on the frequency of cognitive and metacognitive strategies can be the subject of further research.

\section{REFERENCES}

1. Abu-Rabia, S. (1998). Social and cognitive factors influencing the reading comprehension of Arab students learning Hebrew as a second language in Israel. Journal of Research in Reading, 21(3), 201-212.

2. Aebersold, J.A. \& Field, M.L. (1997). From reader to reading teacher: Issues and strategies for second language classrooms. Cambridge: Cambridge University Press.

3. Alptekin, C. (2006). Cultural familiarity in inferential and literal comprehension in L2 reading. System, 34(4), 494-508.

4. Atkinson, D. (1999). TESOL and culture. TESOL Quarterly, 33(4), 625-55.

5. Brown, H. D. (1994). Principles of language learning and teaching (3rded.). Englewood Cliffs, NJ: Prentice Hall Regents.

6. Carrell, P.L. (1983). Some issues in studying the role of schemata or background knowledge in second language comprehension. Reading in a Foreign Language, 1, 81-92. 


\section{International Journal of Current Science Research and Review}

ISSN: 2581-8341

Volume 04 Issue 01 January 2021

DOI: 10.47191/ijcsrr/V4-i1-08, Impact Factor: 6.825

IJCSRR @ 2021

Www.ijcsrr.org

7. Carrell, P. L. (1991). Second language reading: Reading ability or language proficiency? Applied Linguistics, 12(1), 159179.

8. Carrell, P.L., Pharis, B. G. \& Liberto, J.C. (1989). Metacognitive strategy training for ESL reading. TESOL Quarterly, 23(4), 647-678.

9. Carson, J. E., Carrell, P. L., Silberstein, S., Kroll, B., \& Kuehn, P. (1990). Reading writing relationships in first and second language. TESOL Quarterly, 24(2), 245-266.

10. Chamot, A.U. (2004). Issues in language learning strategy research and teaching. Electronic Journal of Foreign Language Teaching, 1(1), 14-26.

11. Chastain, K. (1988). Developing second language skills: Theory and practice ( $3^{\text {rd }}$ ed.). Florida: Harcourt Brace Javanovich Publishers.

12. Coiro, J. \& Dobler, E. (2007). Exploring the online reading comprehension strategies used by sixth-grade skilled readers to search for and locate information on the internet. Reading Research Quarterly, 42(2), 214-257.

13. Davis, J. N., \& Bistodeau, L. (1993). How do L1 and L2 reading differ? Evidence from think aloud protocols. Modern Language Journal, 77(4), 459-472.

14. Droop, M. \& Verhoeven, L. (1998). Background knowledge, linguistic complexity, and second language reading comprehension. Journal of Literacy Research, 30(2), 253-271.

15. El-Dib, M.A.B. (2004). Language learning strategies in Kuwait: Links to gender, language level, and culture in a hybrid context. Foreign Language Annals, 37(1), 85-95.

16. Erten, I.H., \& Razi, H. (2009). The effects of cultural familiarity on reading comprehension. Reading in a Foreign Language, 21(1), 60-77.

17. Fiorito, C. (2000). Foreign language and culture: Some background and some ideas on teaching. NASSP Bulletin, 84(612), 30-34.

18. Fuhong, T. (2004). Cultural schema and reading comprehension. Retrieved June 21, 2013 from www.celea.org.cn/pastversion/lw/pdf/TanFuhong.pdf.

19. Genc, B., \& Bada. E. (2005). Culture in language learning and teaching. The Reading Matrix, 5(1), 73-84.

20. Goodman, K. (1988). The reading process. In P.L. Carrell, J. Devine \& D.E. Eskey (Eds.), Interactive approaches to second language reading (pp. 11-22). New York: Cambridge University Press.

21. Gough, P.B. (1999). The new literacy: Caveat emptor. In J. Oakhill \& R. Beard (Eds.), Reading development and the teaching of reading (pp. 1-12). Oxford: Blackwell Publishers.

22. Grabe, W. (1991). Current developments in second language reading research. TESOL Quarterly, 25, 375-406.

23. Grabe, W., \& Stoller, F.L. (2002). Teaching and researching reading. London: Pearson Education.

24. Hansen-Strain, L. (1989). Orality/literacy and group differences in second-language acquisition. Language Learning, 39(4), 469-96.

25. Harrison, C. (2004). Understanding Reading Development. London: SAGE Publications.

26. Huang, Q. (2009). Background knowledge and reading teaching. Asian Social Knowledge, 5(5), 138-142.

27. Jackson, N.E. (2005). Are university students' component reading skills related to their text comprehension and academic achievement? Learning and Individual Differences, 15(2), 113-39.

28. Jiang, W. (2000). The relationship between culture and language. ELT journal, 54(4), 328- 334.

29. Johnson, P. (1982). Effects on reading comprehension of building background knowledge. TESOL Quarterly, 16(4), 50316.

30. Kachru, Y., \& Smith, L.E. (2008). Cultures, contexts, and world Englishes. New York: Taylor \& Francis.

31. Kaikkonen, P. (1997). Learning culture and foreign language at school aspects of intercultural learning. Language Learning Journal, 15(1), 47-51.

32. Keshavarz, M.H., \& Atai, M.R. (2007). Content schemata, linguistic simplification, and EFL readers' comprehension and recall. Reading in a Foreign Language, 19(1), 19-33.

33. Landry, K.L. (2002). Schemata in second language reading. The Reading Matrix, 2(3), 1-14. 


\section{International Journal of Current Science Research and Review}

ISSN: 2581-8341

Volume 04 Issue 01 January 2021

DOI: 10.47191/ijesrr/V4-i1-08, Impact Factor: 6.825

IJCSRR@ 2021

34. Langer, J.A. (1984). Examining background knowledge and text comprehension. Reading Research Quarterly, 19(4), 468-481.

35. Lee, J.F. (1986). Background knowledge and L2 reading. The Modern Language Journal, 70(4), $350-354$.

36. Levine, M.G., \& Haus, G.J. (1985). The effect of background knowledge on the reading comprehension of second language learners. Foreign Language Annals, 18(5), 391 - 397.

37. Menard-Warwick, J. (2009). Co-constructing representations of culture in ESL and EFL classrooms: Discursive faultlines in Chile and California. The Modern Language Journal, 93(1), 30-45.

38. Moy Yin, K. (1985). The role of prior knowledge in reading comprehension. Reading in a Foreign Language, 3, $375-380$.

39. Nuttall, C. (1996). Teaching reading skills in a foreign language. Oxford: Macmillan Heinemann.

40. Oller, J.W., Chihara, T., \& Sakurai, T. (1989). Background and culture as factors in EFL reading comprehension. Language Testing, 6(6), 143-49.

41. O’Malley, J.M., \& Chamot, A.U. (1990). Learning strategies in second language acquisition. New York: Cambridge University Press.

42. Oxford, R.L. (1990). Language learning strategies: What every teacher should know. New York: Newbury House.

43. Parry, K. (1996). Culture, literacy, and L2 reading. TESOL Quarterly, 30(4), 663-693.

44. Phakiti, A. (2003 a). A closer look at the relationship of cognitive and metacognitive strategy use to EFL reading achievement test performance. Language Testing, 20(1), 26-56.

45. Phakiti, A. (2003 b). A closer look at gender and strategy use in L2 reading. Language learning, 53(4), 649-702.

46. Phakiti, A. (2008). Construct validation of Bachman and Palmer's (1996) strategic competence model over time in EFL reading tests. Language Testing, 25(2), 237-272.

47. Pritchard, R. (1990). The effects of cultural schemata on reading processing strategies. Reading Research Quarterly, 25(4), 273-295.

48. Samuels, S.J., \& Kamil, M.L. (1988). Models of the reading process. In P.L. Carrell, J. Devine \& D.E. Eskey (Eds.), Interactive approaches to second language reading (pp. 22-37). New York: Cambridge University Press.

49. Sasaki, M. (2000). Effects of cultural schemata on students' test-taking processes for cloze tests: A multiple data source approach. Language Testing, 17(1), 85-114.

50. Scarcella, R., \& Oxford, R. (1992). The tapestry of language learning: The individual in the communicative classroom. Boston, MA: Heinle \& Heinle.

51. Sowden, C. (2007). Culture and the 'good teacher' in the English language classroom. ELT Journal, 61(4), 304-310.

52. Stanovich, K.E. (2000). Progress in understanding reading: Scientific foundations and new frontiers. New York: Guilford Press.

53. Tsou, W. (2005). The effects of cultural instruction on foreign language learning. RELC, 36(1), 39-57.

54. Van Oord, L. (2005). Culture as a configuration of learning. Journal of Research in International Education, 4(1), 17193.

Cite this Article: Ebrahim Daryaee Motlagh (2021). The Countervailing Effect of Language Proficiency and Cultural Adaptation on the Frequency of Cognitive-Metacognitive Strategies among EFL Readers. International Journal of Current Science Research and Review, 4(01), 45-52 